\title{
Kesesuaian rencana pembangunan kampus PDD-PSDKU IPB Sukabumi dengan Rencana Tata Ruang Wilayah (RTRW) Kota Sukabumi
}

\author{
Mursalin $^{1 *}$, G. Prayoga ${ }^{1}$, T. Permadi ${ }^{1}$ \\ 1Pusat Penelitian Lingkungan Hidup, Institut Pertanian Bogor, Bogor, Indonesia
}

\begin{abstract}
Abstrak.
Program studi di luar domisili (PDD)-program studi di luar kampus utama (PSDKU) adalah program yang diinisiasi dan difasilitasi oleh Pemerintah Provinsi Jawa Barat bekerja sama dengan IPB yang direncanakan berlokasi di Kota Sukabumi. Tujuannya untuk pemerataan akses pendidikan, peningkatan kapasitas sumber daya manusia, serta pengembangan ilmu pengetahuan dan teknologi di Jawa Barat. Berdasarkan regulasi yang berlaku, rencana pembangunan ini wajib memiliki AMDAL, yang dalam prosesnya wajib mematuhi kesesuaian terhadap rencana tata ruang wilayah (RTRW) kawasan tersebut. Hal itu juga termasuk ke dalam skema penilaian dokumen AMDAL pada uji tahap proyek. Tulisan ini hendak mengkaji bagaimana kesesuaian program pembangunan kampus terhadap RTRW yang ada. Gedung kampus direncanakan dibangun di Kelurahan Babakan, Kecamatan Cibeureum, Kota Sukabumi. Kajian berlangsung pada tahun 2018, dengan melakukan tumpang susun (overlay) menggunakan software ArcGIS versi 10.4.1 antara titik koordinat lokasi rencana pembangunan dengan RTRW Kota Sukabumi periode tahun 2011-2031. Hasil overlay menunjukkan bahwa lokasi rencana pembangunan adalah sesuai berdasarkan tiga poin yang diatur yakni rencana struktur ruang, rencana pola ruang dan rencana penetapan kawasan strategis Kota Sukabumi. Program rencana pembangunan PDD-PSDKU IPB Sukabumi sangat sesuai dengan peruntukan ruang yang diatur, yakni berada di dalam kawasan pendidikan dan pembangunan sarana pendidikan.
\end{abstract}

\begin{abstract}
.
The study program outside the domicile (PDD)-the study program outside the main campus (PSDKU) is a program initiated and facilitated by the West Java Provincial Government in collaboration with IPB which is planned to be located in Sukabumi City. The goal is to equalize access to education, increase human resource capacity and develop science and technology in West Java. Based on the applicable regulations, this development plan must have an EIA document, which in the process must comply with the existing regional spatial plan (RTRW) of this area. This is also included in the EIA document judgement scheme at the project stage test. This paper aimed to examine the suitability of the campus development program toward the existing RTRW. The campus building is planned to be built in Babakan Village, Cibeureum District, Sukabumi City. The study took place in 2018, by overlaying using ArcGIS software version 10.4 .1 between the coordinates of the development plan location with the Sukabumi City RTRW for the period of 2011-2031. The overlay results indicated that the location of the development plan is appropriate based on the three points, namely the spatial structure plan, the spatial pattern plan and the determining of strategic area plan of Sukabumi City. The campus PDD-PSDKU IPB Sukabumi development program is in accordance with the space allocation, which is located in the education area and development of educational facilities area.
\end{abstract}

Keywords: RTRW, PDD-PSDKU, campus, Sukabumi, IPB

\section{PENDAHULUAN}

Pemerintah Provinsi Jawa Barat menginisiasi dan memfasilitasi pengembangan program studi di luar domisili (PDD)-program studi di luar kampus utama (PSDKU) bersama dengan tiga perguruan tinggi ternama di Jawa Barat yaitu ITB, IPB dan Unpad. Program tersebut bertujuan dalam rangka pemerataan akses pendidikan, peningkatan kapasitas sumber daya manusia (SDM), pengembangan ilmu pengetahuan dan teknologi di Jawa Barat. Selain itu,

\footnotetext{
${ }^{*}$ Korespondensi Penulis

Email : mursalin_1000island@yahoo.co.id
} 
program ini juga tercantum dalam izin pendirian perguruan tinggi dan/atau izin penyelenggaraan program studi yang ditetapkan dalam PerMenDikNas Nomor 20 Tahun 2011.

Saat ini, IPB menjadi salah satu perguruan tinggi negeri yang mendapatkan mandat untuk menyelenggarakan PDD-PSDKU di Kota Sukabumi. Dasar hukum penyelenggaraannya: (1) UU Nomor 20 tahun 2003 tentang Sistem Pendidikan Nasional, (2) PerMenDikNas Nomor 20 Tahun 2011 tentang Penyelenggaraan Program Studi Di Luar Domisili Perguruan Tinggi dan (3) PerDa Provinsi Jawa Barat Nomor 25 tahun 2013 tentang Rencana Pembangunan Jangka Menengah Daerah Provinsi Jawa Barat (RPJMD) tahun 2013-2018.

Arah pengembangan tata kelola kampus PDD-PSDKU IPB Sukabumi akan disiapkan menjadi kampus berbasis IT (information technology) meliputi tiga hal besar yaitu transaksi data, data storage dan business intelligent. Arah pengembangan kurikulum sekolah vokasi PDD-PSDKU IPB Sukabumi secara garis besar akan mengusung 6 (enam) dimensi, yaitu hard skill di bidang pertanian terpadu dan lima softskill meliputi leadership, entrepreneurship, social awareness, environmental and sustainability dan ethic/value.

Berdasarkan UU Nomor 32 Tahun 2009 tentang Perlindungan dan Pengelolaan Lingkungan Hidup, PP Nomor 27 Tahun 2012 tentang Izin Lingkungan dan PerMenLH Nomor 5 Tahun 2012 tentang Jenis Rencana Usaha dan/atau Kegiatan yang Wajib memiliki Analisis Mengenai Dampak Lingkungan (AMDAL), bahwa rencana pembangunan kampus PDD-PSDKU IPB Sukabumi dengan luas lahan $\geq 5$ ha $( \pm 14,1 \mathrm{ha})$ wajib memiliki AMDAL. Salah satu syarat wajib dalam proses kajian lingkungan suatu pembangunan adalah terpenuhinya kesesuaian lokasi rencana kegiatan dengan rencana tata ruang wilayah (RTRW) baik nasional, provinsi, atau kabupaten/kota, sesuai ketentuan peraturan perundangan. Merujuk pada PerMenLH Nomor 8 Tahun 2013 tentang Tata Laksana Penilaian dan Pemeriksaan Dokumen Lingkungan Hidup serta Penerbitan Izin Lingkungan, kesesuaian rencana usaha dan/atau kegiatan dengan RTRW termasuk dalam uji tahap proyek (pada skema penilaian AMDAL).

Perencanaan tata ruang mengacu pada metode yang digunakan sebagian besar oleh sektor publik, yakni untuk mempengaruhi distribusi kegiatan dalam satuan ruang tertentu pada masa yang akan datang (CEC 1997 in Morphet 2011). Perencanaan tata ruang juga merupakan instrumen atau alat untuk pembangunan berkelanjutan, karena secara efektif dapat memastikan suatu pembangunan yang berkelanjutan dengan sistem perencanaan baru yang menyeimbangkan kepentingan-kepentingan dari berbagai pihak pengguna ruang (Gorzym-Wilkowski 2017).

Oleh karena itu, urgensi dari kesesuaian terhadap rencana tata ruang ini sangatlah penting untuk ditaati dan dilaksanakan pihak perencana kegiatan. 
Informasi kesesuaian tersebut umumnya disajikan dalam bentuk peta tumpang susun (overlay) antara peta batas tapak proyek rencana kegiatan dengan peta RTRW yang berlaku. Tulisan ini mengkaji bagaimana kesesuaian program rencana pembangunan PDD-PSDKU IPB Sukabumi dengan RTRW yang ada sesuai ketentuan peraturan perundangan.

\section{METODOLOGI}

\subsection{Lokasi kajian dan waktu penelitian}

Gedung kampus PDD-PSDKU IPB Sukabumi direncanakan dibangun di Kelurahan Babakan, Kecamatan Cibeureum, Kota Sukabumi pada titik koordinat $106^{\circ} 57^{\prime} 20^{\prime \prime}$ BT dan 06 56'29" LS (Gambar 1). Luas lahan keseluruhan yang disiapkan untuk pembangunan kampus PDD-PSDKU IPB Sukabumi sebesar $\pm 14,1$ ha yang saat ini masih berupa sawah dan kebun lahan kering. Waktu pelaksanaan kajian berlangsung pada tahun 2018.

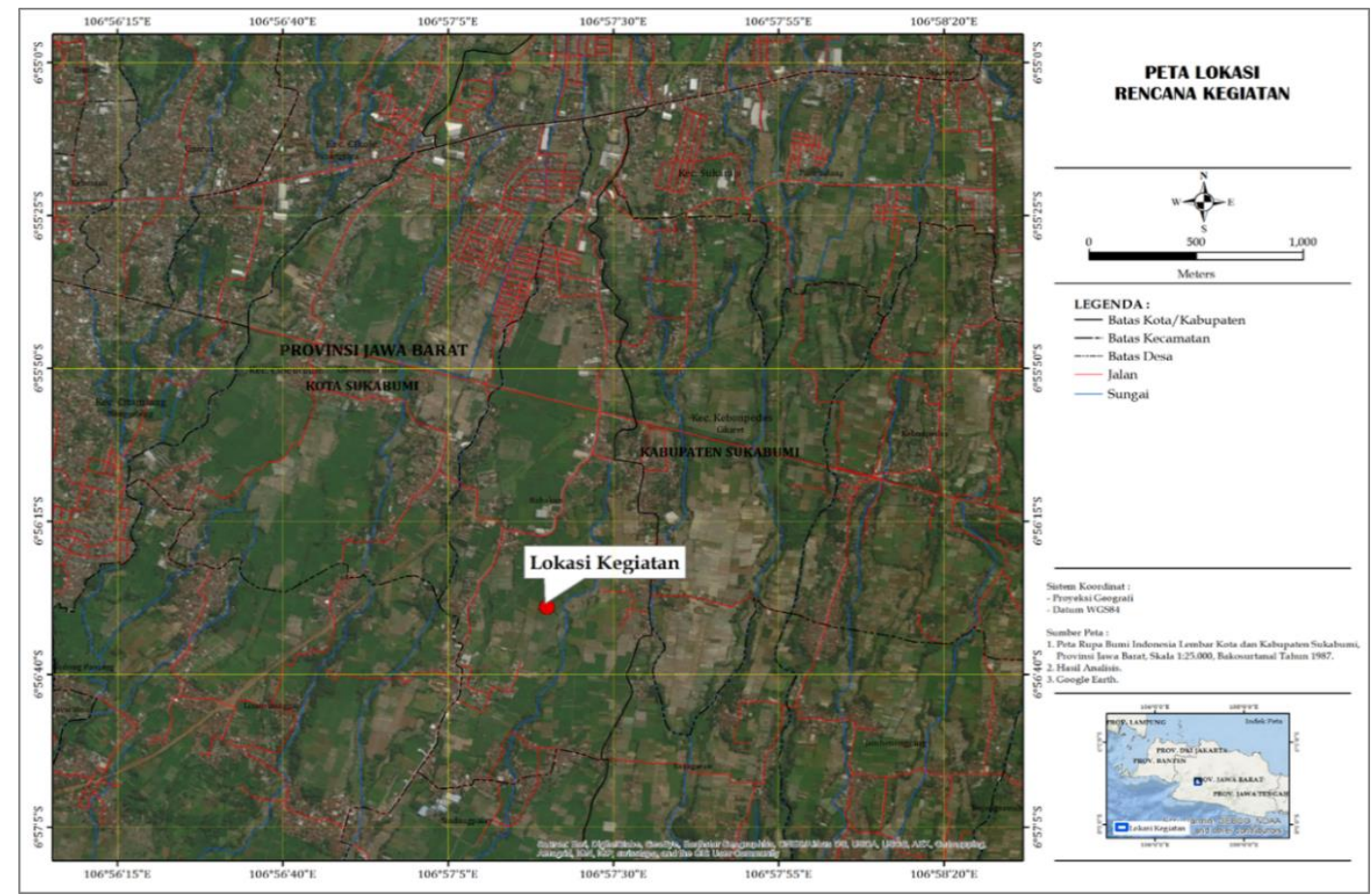

Gambar 1. Lokasi rencana pembangunan kampus PDD-PSDKU IPB di Kota Sukabumi.

\subsection{Prosedur analisis data}

Kajian ini dilakukan dengan melakukan tumpang susun (overlay) antara titik koordinat dari lokasi rencana pembangunan kampus PDD-PSDKU IPB Sukabumi dengan rencana tata ruang wilayah (RTRW) Kota Sukabumi periode tahun 2011-2031. Tumpang susun atau overlay bertujuan untuk mengetahui 
secara visual kesesuaian titik koordinat lokasi terhadap peruntukkan kawasan yang telah diatur dalam RTRW yang berlaku (Dekolo and Oduwaye 2005; Trung et al. 2006; Bunch et al. 2012). Proses overlay menggunakan software ArcGIS versi 10.4.1 (Wang et al. 2014; Effendi et al. 2018a; Effendi et al. 2018b).

\section{HASIL DAN PEMBAHASAN}

Merujuk pada PerDa Kota Sukabumi Nomor 11 Tahun 2012 tentang Rencana Tata Ruang Wilayah Kota Sukabumi Tahun 2011-2031, terdapat tiga poin yang dapat dijadikan perbandingan kesesuaian dengan RTRW Kota Sukabumi. Tiga poin yang dapat dijadikan perbandingan adalah: 1) Kesesuaian terhadap rencana struktur ruang Kota Sukabumi; 2) Kesesuaian terhadap rencana pola ruang Kota Sukabumi; 3) Kesesuaian terhadap rencana penetapan kawasan strategis kota (KSK) Sukabumi.

\subsection{Kesesuaian terhadap rencana struktur ruang Kota Sukabumi}

Lokasi rencana pembangunan kampus PDD-PSDKU IPB Sukabumi berdasarkan rencana struktur ruang dalam RTRW Kota Sukabumi termasuk dalam Sub Wilayah Kota (SWK) V (Gambar 2). SWK V dengan luas \pm 623 ha salah satunya mencakup sebagian Kelurahan Babakan. Berdasarkan fungsinya, SWK V memiliki fungsi sebagai lokasi rencana pengembangan pendidikan tinggi dan perkantoran pemerintahan.

Fakta di atas menunjukkan bahwa lokasi yang akan digunakan sebagai rencana pembangunan kampus PDD-PSDKU IPB Sukabumi, tepatnya di Kelurahan Babakan, sangatlah sesuai dengan peruntukan rencana struktur ruang yang ada. Pendidikan tinggi yang akan disediakan oleh IPB melalui Program Pemerintah Provinsi Jawa Barat ini juga dapat menjadi solusi bagi kurangnya sarana pendidikan tinggi dengan kualitas yang mumpuni di Kota maupun Kabupaten Sukabumi.

\subsection{Kesesuaian terhadap rencana pola ruang Kota Sukabumi}

Berdasarkan rencana pola ruang Kota Sukabumi dalam RTRW yang ada, lokasi rencana pembangunan kampus PDD-PSDKU IPB Sukabumi masuk ke dalam rencana kawasan budi daya. Rencana Kawasan Budi Daya sebagaimana dimaksud dalam Pasal 37 ayat (1) huruf b PerDa Kota Sukabumi Nomor 11 Tahun 2012, meliputi kawasan perumahan, perdagangan dan jasa, peruntukan industri, ruang terbuka non hijau, perkantoran, pariwisata, peruntukan ruang bagi sektor informal dan peruntukan lainnya (pelayanan kesehatan, pelayanan pendidikan, pertanian, penelitian, pergudangan, pertahanan dan keamanan). 


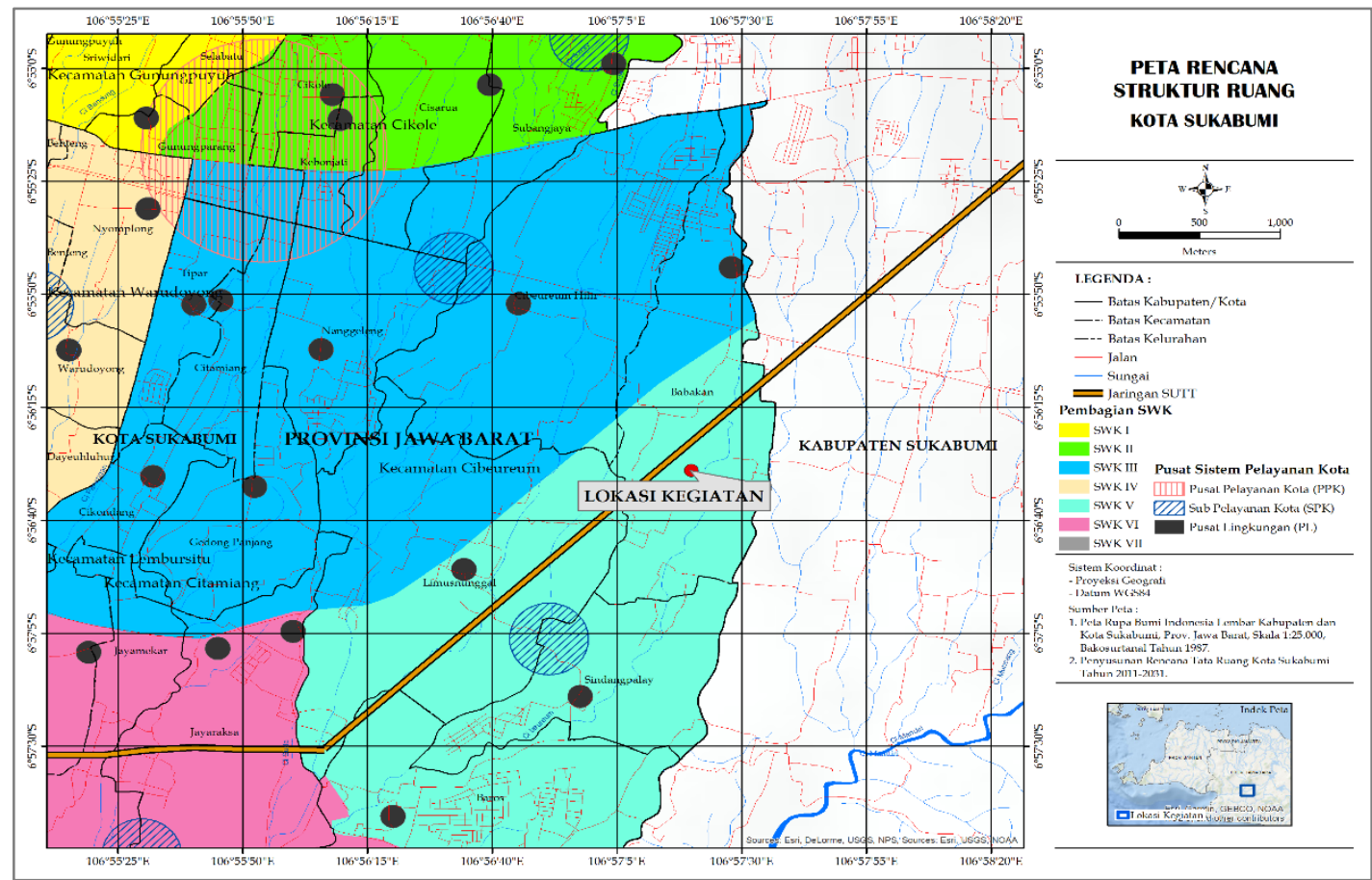

Gambar 2. Kesesuaian lokasi rencana pembangunan PDD-PSDKU IPB di Kota Sukabumi dengan rencana struktur ruang dalam RTRW Kota Sukabumi periode tahun 2011-2031.

Hasil overlay terhadap peta rencana pola ruang Kota Sukabumi 2011-2031, lokasi rencana pembangunan berada pada kawasan peruntukan lainnya, yaitu sebagai kawasan pelayanan pendidikan (Gambar 3). Hal tersebut semakin memperkuat hasil sebelumnya, karena dengan begitu terdapat dua bukti yang menunjukkan bahwa lokasi rencana pembangunan kampus ini sangat sesuai dengan peruntukan yang tertera dalam RTRW Kota Sukabumi.

\subsection{Kesesuaian terhadap rencana penetapan kawasan strategis kota (KSK) Sukabumi}

Penetapan KSK Sukabumi meliputi 3 arah pengembangan yakni KSK pusat kota dengan sudut kepentingan ekonomi, KSK lingkar selatan dengan sudut kepentingan ekonomi dan KSK Cibeureum dengan sudut kepentingan sosial budaya. Secara administratif dan diperkuat dengan hasil overlay peta (Gambar 4), lokasi rencana pembangunan kampus berada pada KSK Cibeureum. Berdasarkan PerDa Kota Sukabumi Nomor 11 Tahun 2012 Pasal 65 Ayat (2), KSK Cibeureum direncanakan sebagai daerah penataan kawasan zona inti pendidikan dan kawasan perkantoran pemerintah, serta pengembangan fasilitas pendukung kegiatan pendidikan dan fasilitas transportasi penunjang kawasan pendidikan \& kawasan perkantoran. 


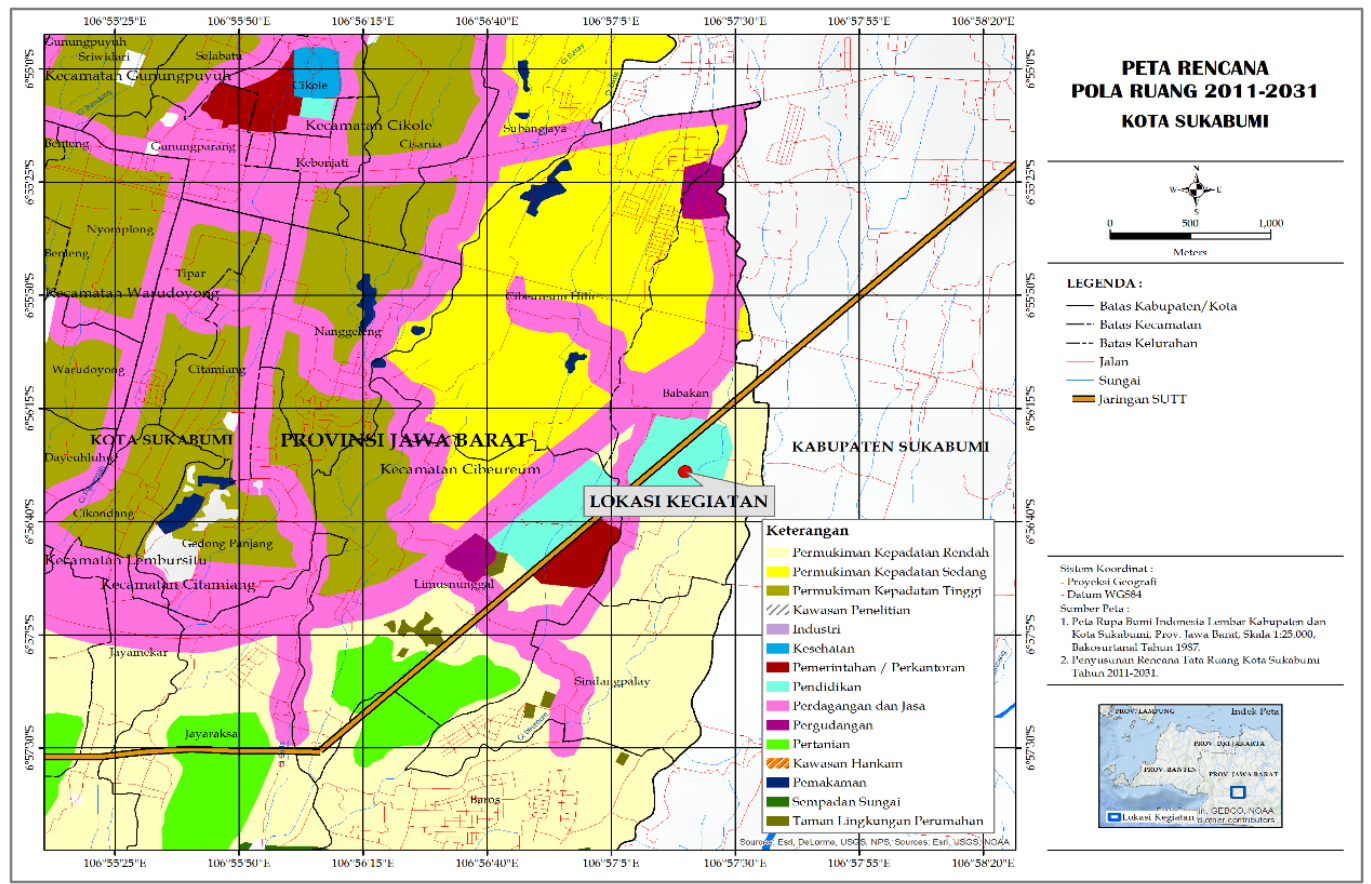

Gambar 3. Kesesuaian lokasi rencana pembangunan PDD-PSDKU IPB di Kota Sukabumi dengan rencana pola ruang dalam RTRW Kota Sukabumi periode tahun 2011-2031.

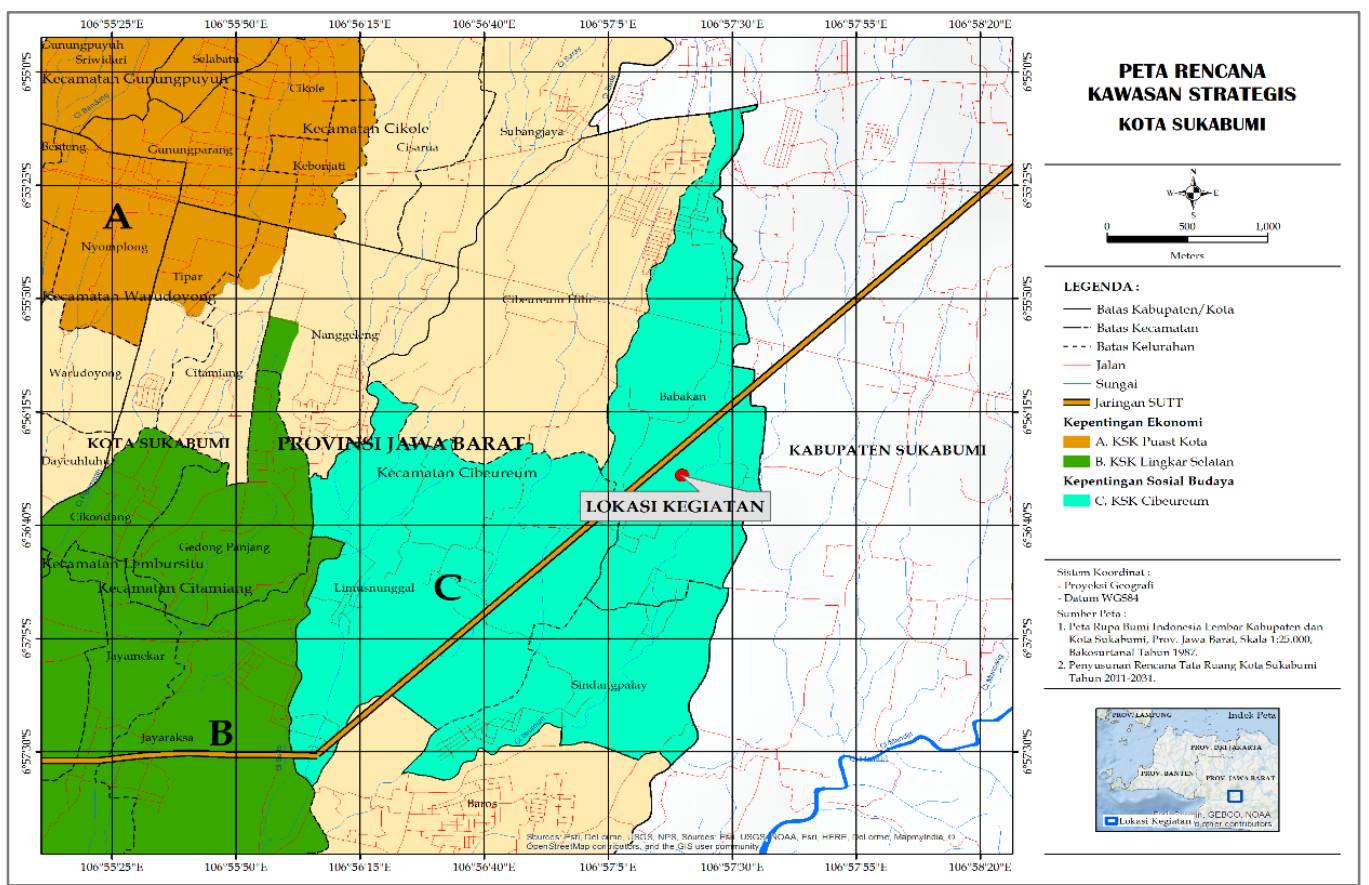

Gambar 4. Kesesuaian lokasi rencana pembangunan PDD-PSDKU IPB di Kota Sukabumi dengan rencana penetapan kawasan strategis dalam RTRW Kota Sukabumi periode tahun 2011-2031. 
Pembangunan kampus PDD-PSDKU IPB Sukabumi menilik pada sisi kebutuhan akan pendidikan tinggi di Kota/Kabupaten Sukabumi, cukup penting untuk dilakukan. Pendidikan adalah faktor penting dalam rangka peningkatan kualitas SDM guna menunjang keberhasilan pembangunan di suatu daerah. Menurut Suparno (2009) in Purnomo (2012), SDM merupakan hal yang penting karena keunggulan kompetitif sebuah negara pada akhirnya akan ditentukan oleh kualitas SDM yang dimiliki negara tersebut.

Salah satu variabel untuk melihat kualitas SDM yang sekaligus juga dasar adanya pendirian kampus PDD-PSDKU IPB Sukabumi adalah Angka Partisipasi Kasar Jenjang Pendidikan Tinggi (APK PT). APK PT adalah perbandingan antara jumlah murid pada jenjang pendidikan tinggi dengan penduduk kelompok usia sekolah yang sesuai. Nilai dari APK PT dinyatakan dalam bentuk persentase. APK PT Kota dan Kabupaten Sukabumi dalam kurun waktu 2011-2015 mengalami kecenderungan meningkat, namun relatif masih jauh berada di bawah APK PT Nasional (31,1\%), terutama untuk Kabupaten Sukabumi (Tabel 1). Nilai tersebut akan semakin jauh tertinggal apabila dibandingkan dengan APK PT Nasional milik negara lain seperti Malaysia, Thailand, Singapura dan terutama Korea Selatan (Tabel 2).

Tabel 1. Angka partisipasi kasar jenjang pendidikan tinggi (APK PT) di Kota dan Kabupaten Sukabumi tahun 2011-2015.

\begin{tabular}{cccc}
\hline \multirow{2}{*}{ No } & \multirow{2}{*}{ Tahun } & Kota Sukabumi & APK PT $(\%)$ \\
\cline { 3 - 4 } & 2011 & 13,31 & Kabupaten Sukabumi \\
\hline 1 & 2012 & 20,52 & 7,83 \\
2 & 2013 & 27,05 & 7,83 \\
3 & 2014 & 23,35 & 17,57 \\
4 & 2015 & 21,63 & 19,40 \\
5 & & & 12,64 \\
\hline
\end{tabular}

Sumber : BPS Provinsi Jawa Barat (2018)

Tabel 2. Angka partisipasi kasar jenjang pendidikan tinggi (APK PT) di beberapa negara Asia.

\begin{tabular}{ccc}
\hline No & Negara & APK PT (\%) \\
\hline 1 & Malaysia & 38,0 \\
2 & Thailand & 54,0 \\
3 & Singapura & 78,0 \\
4 & Korea Selatan & 98,2 \\
\hline
\end{tabular}

Sumber : Republika.co.id (2017)

Selama kurun waktu 2014-2016, berdasarkan data BPS Kota Sukabumi (2017), persentase rata-rata jumlah penduduk usia sekolah cukup banyak yakni sebesar 22,33\% atau sebanyak 70.996 jiwa. Jumlah penduduk rata-rata pada usia SLTA kurang lebih sebanyak 22,65\% atau 16.016 jiwa. Jumlah tersebut 
sangatlah besar dan sebanyak kurang lebih 16 ribu jiwa tersebut adalah jumlah calon potensial yang akan selalu tersedia untuk melanjutkan ke jenjang pendidikan tinggi setiap tahunnya. Jumlah tersebut pula yang kini membutuhkan sarana atau wadah untuk menampung potensi yang dimiliki.

Hadirnya IPB di Kota Sukabumi melalui program PDD-PSDKU IPB Sukabumi dirasa akan menjadi solusi bagi kekurangan yang saat ini dimiliki. Apalagi IPB berfokus pada bidang ilmu pertanian secara luas mulai dari pertanian itu sendiri, lalu perikanan, kehutanan dan peternakan. Selain itu, dengan visinya menjadi kampus berbasis IT, bidang-bidang ilmu tersebut akan diarahkan pada aplikasi bersama teknologi masa kini, sehingga modernisasi akan semakin dikenal oleh para civitas akademikanya, yang juga memiliki potensi besar yang perlu dikembangkan dengan sentuhan ilmu pengetahuan dan teknologi. Potensi besar tersebut seperti adanya ekosistem laut disertai aktivitas pelabuhannya, ekosistem hutan dan potensi peternakan.

\section{KESIMPULAN DAN SARAN}

Berdasarkan pada uraian di atas, bahwa program rencana pembangunan PDD-PSDKU IPB Sukabumi sangat sesuai dengan RTRW Kota Sukabumi periode tahun 2011-2031. Berdasarkan rencana struktur ruang, rencana pola ruang dan rencana penetapan kawasan strategis Kota Sukabumi, lokasi rencana pembangunan kampus berada di dalam kawasan pendidikan dan pembangunan sarana pendidikan.

\section{UCAPAN TERIMAKASIH}

Terima kasih disampaikan kepada Kementerian Riset, Teknologi dan Pendidikan Tinggi, Institut Pertanian Bogor Cq. Program Studi di Luar Domisili/Program Studi di Luar Kampus Utama Institut Pertanian Bogor di Kota Sukabumi dan Pemerintah Kota Sukabumi yang telah memfasilitasi kajian ini dan atas kerja samanya dalam penyediaan data serta informasi sehingga tulisan ini dapat terselesaikan.

\section{DAFTAR PUSTAKA}

[BPS] Badan Pusat Statistik Kota Sukabumi. 2017. Kota Sukabumi dalam angka 2017. BPS Kota Sukabumi. Sukabumi.

[BPS] Badan Pusat Statistik Provinsi Jawa Barat. 2018. Angka partisipasi kasar (APK) menurut kabupaten/kota dan jenjang pendidikan tahun 2011-2015 [internet]. Tersedia di: https://jabar.bps.go.id/statictable/2016/10/02/ 99/angka-partisipasi-kasar-apk-menurut-kabupaten-kota-dan-jenjangpendidikan-tahun-2011-2015.html. 
Bunch MJ, Kumaran TV and Joseph R. 2012. Using geographic information systems (GIS) for spatial planning and environmental management in India: critical considerations. International Journal of Applied Science and Technology 2(2):40-54.

Dekolo SO and Oduwaye L. 2005. GIS in urban and regional planning. NITP Lagos State Chapter CPD Workshop. 1-15.

Effendi H, Permatasari PA, Muslimah S and Mursalin. 2018a. Water quality of Cisadane River based on watershed segmentation. IOP: Earth and Environmental Science 149(2018) 012023.

Effendi H, Sabila MF and Setiawan Y. 2018b. Correlation between water quality and land use change in Ciliwung Watershed. Nature Environment and Pollution Technology 17(1):139-144.

Gorzym-Wilkowski WA. 2017. Spatial planning as a tool for sustainable development: Polish realities. Barometr Regionalny 15(2):75-85.

Morphet J. 2011. Effective practice in spatial planning. Routledge. New York.

PerDa (Peraturan Daerah) Kota Sukabumi Nomor 11 Tahun 2012 tentang rencana tata ruang wilayah Kota Sukabumi tahun 2011-2031.

PerDa (Peraturan Daerah) Provinsi Jawa Barat Nomor 25 tahun 2013 tentang rencana pembangunan jangka menengah daerah Provinsi Jawa Barat (RPJMD) tahun 2013-2018.

PerMenDikNas (Peraturan Menteri Pendidikan Nasional) Nomor 20 Tahun 2011 tentang penyelenggaraan program studi di luar domisili perguruan tinggi.

PerMenLH (Peraturan Menteri Negara Lingkungan Hidup) Nomor 5 Tahun 2012 tentang jenis rencana usaha dan/atau kegiatan yang wajib memiliki analisis mengenai dampak lingkungan.

PerMenLH (Peraturan Menteri Negara Lingkungan Hidup) Nomor 8 Tahun 2013 tentang tata laksana penilaian dan pemeriksaan dokumen lingkungan hidup serta penerbitan izin lingkungan.

PP (Peraturan Pemerintah) Nomor 27 Tahun 2012 tentang izin lingkungan.

Purnomo A. 2012. Karakteristik penganggur terbuka, setengah penganggur dan pertumbuhan ekonomi di Propinsi Jawa Timur (analisis data Sakernas Agustus tahun 2010). Jurnal Bumi Indonesia 1(2):111-120.

Republika.co.id. 2017. APK perguruan tinggi tak sebanding dengan jumlah kampus [internet]. Tersedia di: http://www.republika.co.id/berita/pendi dikan/dunia-kampus/17/11/20/ozpyyo280.

Trung NH, Tri LQ, van Mensvoort MEF and Bregt AK. 2006. Application of GIS in land-use planning: a case study in the coastal Mekong Delta of Vietnam. International Symposium on Geoinformatics for Spatial Infrastructure Development in Earth and Allied Sciences 1-6. Japan-Vietnam 
Geoinformatics Consortium (JVGC) Institute for Environment and Resources (IER-HCMC).

UU (Undang-Undang) Nomor 20 tahun 2003 tentang sistem pendidikan nasional. UU (Undang-Undang) Nomor 32 Tahun 2009 tentang perlindungan dan pengelolaan lingkungan hidup.

Wang Q, M'Ikiugu MM and Kinoshita I. 2014. A GIS-based approach in support of spatial planning for renewable energy: a case study of Fukushima, Japan. Sustainability 6(4):2087-2117. 